\title{
Pride and Prejudice and Zombies: um corpo (textual) zumbificado
}

Ivoneide Soares dos Santos de Jesus ${ }^{a}$

Vinicius Carvalho Pereira ${ }^{b}$

\section{Resumo}

Ao final da primeira década do novo milênio, o mercado editorial assistiu à ascensão de uma nova forma de composição textual, o mashup literário, produzido através de movimentos de leitura e escritura que potencializam a noção barthesiana do texto como "tecido de citações". Para tanto, o mashup se baseia em procedimentos de fragmentação de uma obra clássica para nela enxertar elementos caros à cultura pop hodierna. Pride and Prejudice and Zombies, de Jane Austen e Seth Grahame-Smith, foi o precursor dessa tendência, abrindo caminho para um novo filão na indústria de best-sellers produzidos segundo os mesmos procedimentos. Diante de tal contexto, o presente artigo analisa a obra Pride and Prejudice and Zombies a fim de entender, em termos de imanência, os procedimentos pelos quais, nas entranhas do romance, fundiu-se a escrita oitocentista de Austen com a contemporânea de Grahame-Smith, formando uma híbrida obra, também ela zumbi, dado que habita um entre-lugar entre a escrita de uma autora morta e de um autor vivo. Desse modo, adotando a imagem do zumbi não só como elemento acrescido ao enredo, mas como processo de escrita e adaptação - pela zumbificação do romance de Jane Austen -, objetivamos analisar as entranhas de Pride and Prejudice and Zombies, partindo do conceito de mashup literário, gênero que ensejou a mistura entre diferentes textos na obra, por meio de procedimentos de hibridização.

Palavras-chave: mashup literário; zumbi; procedimentos de hibridação.

\footnotetext{
${ }^{a}$ Mestre em Estudos de Linguagem pela UFMT, membro do grupo CNPq SEMIC - Semióticas Contemporâneas. E-mail: ivykenth@hotmail.com

bProfessor do Departamento de Letras da Universidade Federal do Mato Grosso, doutor em Ciência da Literatura pela UFRJ. E-mail: viniciuscarpe@gmail.com
} 


\section{Introdução}

Em 2009, nascia das entranhas do mercado literário um novo tipo de escrita na qual se recombinavam textos de autores de diferentes contextos. A ideia era revisitar clássicos da literatura mundial e repaginá-los, dando-lhes um toque moderno através da inserção de elementos insólitos. Essa ideia de mesclar formas textuais fez emergir no campo dos gêneros textuais uma nova categoria, o mashup literário (GOMES, 2013), dentro de uma também nova categoria mais abrangente: o "gênero popular de ficção misturada" (MURPHY, 2013, n.p.). Esse mix discursivo teve como ponto de partida a publicação de Pride and Prejudice and Zombies, cuja autoria é atribuída à já aclamada escritora inglesa Jane Austen e ao norte-americano até então desconhecido Seth Grahame-Smith. Nessa obra, faz-se presente o texto austeniano com um ínfimo acréscimo de passagens envolvendo zumbis por parte do autor norteamericano contemporâneo.

A iniciativa de levar o mashup para o universo literário veio da editora de Seth Grahame-Smith, a Quirk Books, que encomendou um best-seller que inserisse elementos do gênero horror na obra de Austen. Pride and Prejudice and Zombies foi um sucesso de vendas, amparado pela "onda zumbi" que se fazia presente no momento da publicação, dando origem a uma verdadeira febre de romances com essa temática.

A grande exploração da temática sobrenatural levou a editora Quirk Books a repensar o próprio processo de criação de Pride and Prejudice and Zombies, fazendo o romance retornar às mãos de seu escritor para uma revisão, a fim de que fossem retirados mais trinta por cento do texto-fonte, para inserção de mais passagens com zumbis, totalizando uma retirada de quarenta e cinco por cento do texto escrito por Jane Austen (QUIRK BOOKS, 2014). Essa reedição recebeu o nome de Pride and Prejudice and Zombies: Deluxe Heirloom Edition, mas não foi lançada no Brasil. Os leitores brasileiros têm acesso apenas a Pride and Prejudice and Zombies, traduzido em 2010 pela editora Intrínseca, com o título de Orgulho e Preconceito e Zumbis.

O objeto de análise nas próximas páginas deste trabalho

1 Texto original: "popular genre category of mashup fiction". é a primeira versão de Pride and Prejudice and Zombies, composta por oitenta e cinco por cento do texto-fonte e quinze por cento de enxertos de Grahame-Smith (COLLINS, 2009; GROSSMAN, 
2009; KELLOGG, 2009; SCHUESSLER, 2009a; 2009b). Neste artigo, objetivamos analisar o processo que hibridizou a escrita de Jane Austen e a de Grahame-Smith formando um corpo textual único, que aqui chamamos de obra-zumbi, conforme os argumentos mais à frente apresentados. Para tanto, adotamos a hibridização, fenômeno inerente às produções contemporâneas, como elemento-chave na constituição de Pride and Prejudice and Zombies. Assim, revelamos os movimentos de leitura que, no mashup, fragmentaram, fenderam, enxertaram e hibridizaram o texto de Austen, formando um corpo (textual) zumbificado.

\section{Pride and Prejudice and Zombies: o corpo}

Em sua contracapa, Pride and Prejudice and Zombies (AUSTEN; GRAHAME-SMITH, 2009) é apresentado como uma "uma edição expandida do romance mais amado de Jane Austen com cenas de zumbis mutilando ossos" (AUSTEN; GRAHAMESMITH, 2009, contracapa, tradução nossa) ${ }^{2}$. Na obra, o calmo vilarejo de Meryton foi acometido por uma misteriosa praga que vem levantando os mortos de suas tumbas, devolvendolhes em parte a vida. A heroína do romance, Elizabeth Bennet, treinada nas artes marciais chinesas, juntamente com suas irmãs, é encarregada pelos governantes ingleses de proteger o local onde vivem. Elizabeth está determinada a dar um fim à ameaça zumbi, porém é distraída pela chegada do altivo e arrogante Sr. Darcy. Ainda na descrição da contracapa, o romance é descrito como uma "deliciosa comédia de costumes com uma disputa civilizada entre os dois amantes - e disputas ainda mais violentas com um campo de batalha encharcado de sangue"33 (AUSTEN; GRAHAME-SMITH, 2009, contracapa,

2 Texto original: "An expanded edition of the beloved Jane Austen novel featuring allnew scenes of bonecrunching zombie mayhem".

3 Texto original: "Delightful comedy of manners with plenty of civilized sparring between two young lovers - and even more violent sparring on the blood-soaked battlefield". tradução nossa).

Não há no romance uma explicação para a origem da praga que há cinquenta e cinco anos corrompe os cemitérios ingleses. $\mathrm{O}$ que se sabe é que os túmulos enjeitam aqueles que lá foram enterrados, os quais retornam como zumbis. Essa situação faz com que todos tenham que se preparar para combatê-los. Na localidade de Hertfordshire, o Sr. Bennet envia suas filhas, as cinco moças (a mais velha, Jane; a segunda mais velha e protagonista do romance, Elizabeth; a terceira, Mary; Catherine, apelidada como "Kitty"; e a mais jovem, Lydia), para 
um treinamento nas "artes mortais" no Templo de Shaolin pelas mãos do Mestre Pei Liu, na China.

O romance adaptado segue o esqueleto do texto-fonte ${ }^{4}$, comportando os sessenta e um capítulos, com todos os personagens e situações vividas em Orgulho e Preconceito. A ossatura de Orgulho e Preconceito é sustentada por três grandes colunas: I) Danças, II) Visitas e III) Casamentos (MONAGHAM, 1987 apud SANTANA, 2012). A diferença é que, na releitura de Pride and Prejudice and Zombies, a esses eixos são acrescidas as cenas com os zumbis.

$\mathrm{Na}$ coluna da ossatura, encontram-se os bailes, que promovem a interação e socialização segundo interesses amorosos (MONAGHAM, 1987 apud SANTANA, 2012). O texto de Austen foi publicado em uma época em que o decoro, principalmente por parte da mulher, deveria ser seguido como regra ou lei; nesse contexto, ir a um baile significava estar "livre" para se divertir, o que incluía a dança e o flerte. Nesse sentido, os bailes eram os locais e os momentos apropriados para o cortejo, marcando a aproximação entre os personagens e a evolução de uma amizade que poderia terminar em um compromisso amoroso.

Em Pride and Prejudice and Zombies, é no baile de Meryton, o primeiro do romance, que acontece a primeira invasão de zumbis. Nessa invasão, as irmãs Bennet se lançam em combate contra os mortos-vivos. A cena descreve que, após o recinto ser invadido, o pai clama pelo "Pentagrama da Morte", e as irmãs formam no centro da sala uma estrela e iniciam os ataques contra os invasores.

Nesta cena, fica evidente que o romance de Austen entrou em diálogo direto com o século XXI e recebeu influência da cultura pop contemporânea, apesar de ter sido publicado no século XIX. A entrada dos zumbis no texto abriu espaço para que outros elementos também adentrassem a narrativa, tais como traços de filmes de ação, principalmente os de lutas marciais. Aqui se destacam influências como as do filme Kill Bill, do diretor americano Quentin Tarantino. Na película, a

Termo usado por Linda Hutcheon em $A$ teoria da adaptação para designar um texto "original", aqui usado com referência a Orgulho e Preconceito. protagonista Beatrix Kiddo vira uma lutadora em busca de vingança contra aqueles que tentaram matá-la, executando movimentos de luta quase circenses, como o "Pentagrama da Morte", de Pride and Prejudice and Zombies. 
5 Raymond Williams (1973) discute, a partir do romance, as relações entre a burguesia rural e a aristocracia inglesa. Para o autor, ambos os grupos se configurariam como apenas uma classe social, estando a diferença entre eles assentada em um desnível financeiro. No caso de Orgulho e Preconceito, não há menção no texto que configure os Bennet como burgueses, pois não há no romance elementos que indiquem que tal família detenha os meios de produção. Na visão de Williams, Elizabeth e Darcy pertenceriam, pois, à classe dos aristocratas. Entretanto, para este estudo, consideramos ambas como classes sociais distintas. Nesta linha de pensamento, e apesar de os meios de subsistência dos Bennet não serem explicitamente descritos em Orgulho e Preconceito, poderíamos afirmar que esta família também poderia ser parte dos gentry - um tipo de nobreza rural que, embora não possuísse títulos, possuía os mesmos valores que o restante da aristocracia inglesa.
Enquanto as cenas dos bailes levam o leitor a perceber esses diálogos entre a cultura pop e o romance oitocentista, o segundo eixo do romance - as visitas - possibilita a interação entre as personagens, despertando o interesse e a possibilidade de uma união (MONAGHAM, 1987 apud SANTANA, 2012). Ao longo do romance, as visitas se tornam o elemento principal para que ocorram as batalhas entre humanos e zumbis.

No enredo, os ataques de zumbis acontecem em geral quando alguém vai fazer uma visita a outra propriedade. Charlotte Lucas, por exemplo, foi mordida em uma visita. Além disso, Bingley abandonou Jane porque ela poderia ter sido contaminada no momento em que fora visitar Netherfield Park. Se os momentos entre o sair de casa e chegar a outro local não foram explorados por Austen em seu romance, em Pride and Prejudice and Zombies, Grahame-Smith se apossa disso e faz dessas passagens o ensejo para dar movimento ao texto austeniano.

Em sua análise de Orgulho e Preconceito, David Monaghan aponta que o casamento, a camada mais profunda do romance, representaria a união das classes, portanto, teria o papel de resolver os conflitos. A união entre Charlotte Lucas e o pároco William Collins resolveria os problemas financeiros dela e a necessidade dele quanto a ter uma esposa conforme os ditames da igreja, enquanto o de Lydia e Wickham restauraria a honra das Bennet, abrindo caminho para a união de suas irmãs mais velhas (MONAGHAM, 1987 apud SANTANA, 2012).

Em Pride and Prejudice and Zombies, o casamento de Elizabeth e Darcy, que une as classes de lutadores de arte marciais (pois Mr. Darcy também é um guerreiro, mas treinado no Japão), une simbolicamente também as classes sociais, tal como no romance de Austen, só que com novas camadas de significação. Ao longo da narrativa, nota-se a disputa entre as artes chinesas, representadas pelas irmãs Bennet, e as artes japonesas, representada pelo Sr. Darcy e sua tia Lady Catherine de Bourgh. Cria-se assim um paralelo: burguesia rural/artes chinesas versus aristocracia/artes japonesas, o que, em certa medida, vai ao encontro de parte do imaginário ocidental contemporâneo sobre essas nações orientais ${ }^{5}$.

Na próxima seção, analisaremos as operações intertextuais que se dão no corpo textual para dar à luz Pride and Prejudice 
and Zombies, revelando aqui os movimentos de leitura e escritura presentes na mistura entre a escrita de Austen e a de Grahame-Smith.

\section{Uma autópsia literária nas entranhas da obra-zumbi}

Se mostrado em uma imagem de raio- $\mathrm{X}$, Pride and Prejudice and Zombies teve quinze por cento do texto de Austen retirado e, nessas lacunas, foram enxertados outros quinze por cento de passagens zumbificadas; ou seja, o romance manteve mais de três quartos do texto-fonte. Por meio de processos de fragmentação, em que o texto-fonte sofre uma espécie de fracionamento, seguido de uma (re)combinação com trechos contendo zumbis, pode-se dizer que o romance foi zumbificado.

Aqui, o zumbi metaforiza o modo de composição da narrativa, cheia de fragmentos extirpados e enxertados, que, recombinados com o enredo do texto-fonte, formam algo que denominamos obra-zumbi. Por sua vez, esta revelaria as mazelas de sua criação, tendo em vista que o zumbi seria um corpo não retalhado, mas fragmentado.

O retalho é uma forma de recorte em pequenos pedaços, enquanto o fragmento é produto de uma desintegração, um pedaço que se desgarra, dando seu lugar a outro. Um texto zumbificado é uma complexa rede de (micro)estruturas acopladas formando um sistema único, mas híbrido. Pride and Prejudice and Zombies é, portanto, uma obra-zumbi. O monstro zumbi, como elemento central de Pride and Prejudice and Zombies, revela como o processo de hibridização ocorreu no interior da narrativa. No plano do enunciado, o romance é atravessado por uma série de cenas zumbificadas que se costuram ao texto-fonte, formando um todo híbrido. Só se sabe o que pertence a Austen por meio de comparações com Orgulho e Preconceito. Nesta seção, analisamos, portanto, as entranhas desse corpo.

Ao ser questionado em uma entrevista sobre como foi o processo de construção de Pride and Prejudice and Zombies, Seth Grahame-Smith explicou que o trabalho de "escritura" aconteceu em duas etapas. Na primeira, o autor se dedicou à leitura de Orgulho e Preconceito, realçando na cor vermelha as passagens que poderiam ser extirpadas para inserir os enxertos com zumbis. No segundo momento, Grahame- 
Smith colou em seu computador um arquivo contendo o texto-fonte e iniciou a fase de subtração definitiva dos trechos de Austen, para inserção dos enxertos contendo os zumbis. Periodicamente, ele verificava a dosagem entre sua escrita e a de Austen (KELLOGG, 2009), procurando assim manter mais trechos austenianos que os seus. Na visão do próprio escritor, o processo de "escrever" Pride and Prejudice and Zombies foi como efetuar uma espécie microcirurgia em Orgulho e Preconceito (TAKAHASHI, 2009).

Note-se, nesse caso, a dimensão metatextual do relato, na medida em que, ao mesmo tempo em que o narrador está construindo o romance, o escritor está contando como fez para escrever uma obra em coautoria com Jane Austen. No nível de enunciado, a horda de zumbis que invade o primeiro baile do romance conota o nível da enunciação, em que o escritor Seth Grahame-Smith invadiu um romance clássico, apropriando-se da escrita alheia. Os zumbis se movimentam no interior da narrativa, abocanhando parágrafos, sentenças inteiras e palavras, fazendo fluir mais rápida a leitura. $\mathrm{O}$ autor, como um zumbi, morde trechos, corta diálogos e mata personagens, abrindo sendas para movimentos de sentidos e imagens na narrativa. Por outro lado, a perda de personagens ao longo da narrativa simbolizaria ainda o próprio processo de transcriação do texto, em que cada personagem morto pode ser entendido como um elemento retirado, um parágrafo, uma frase ou um diálogo extirpado por Grahame-Smith ao longo de sua escritura.

Nesse jogo de cortes e incisões, não podemos perder de vista a dimensão erótica de toda intertextualidade no âmbito literário. Roland Barthes, em O prazer do texto (1987), faz uma oposição entre texto de prazer e texto de fruição. Para Barthes, o primeiro causa contentamento, euforia, vem da cultura e não rompe com os ditames dela, o que nos leva a entender que, hoje, Orgulho e Preconceito pode ser entendido como esse tipo de texto, indo ao encontro de nossos horizontes de expectativa quanto ao que seja um texto literário. Por outro lado, tem-se Pride and Prejudice and Zombies, o texto de fruição, que desconforta e faz vacilar as bases culturais, históricas e psicológicas do leitor. Barthes apresenta o texto não como algo que causa fetiche, mas como o próprio fetiche. 
O texto é um objeto fetiche e esse fetiche me deseja. O texto me escolheu, através de toda uma disposição de telas invisíveis, de chicanas seletivas: o vocabulário, as referências, a legibilidade, etc.; e, perdido no meio do texto [...] há sempre o outro, o autor. [...] mas no texto, de uma certa maneira, eu desejo o autor: tenho necessidade de sua figura (BARTHES, 1987, p.37).

O desejo pelo autor faz querer imitá-lo, trabalhar com seu texto, mas não apenas copiar sua ideia, e sim manipular sua massa textual, fazendo de sua escrita a minha, tornando o outro um eu. Trabalhar a massa textual requer um olhar profundo sobre o texto analisado, um olhar para suas entranhas.

N'O trabalho da citação, Antoine Compagnon (1996) metaforiza em linguagem cirúrgica o trabalho que se tem ao explorar o interior de um texto. Segundo o autor, o texto sofre uma espécie de fragmentação na qual se inserem em seu corpo elementos que lhe são exteriores: "o texto é um trabalho da citação, uma sobrevivência ou, antes, uma manifestação do gesto arcaico de recortar-colar [...], ele é uma rede de forças que trabalham e deslocam" (COMPAGNON, 1996, p.58).

Compagnon trabalha com a citação, afirmando que esta só obtém significação ao longo de um processo, realizandose ao longo de um trabalho. A escrita como ato de citação remeteria à noção de dialogicidade textual, em que os discursos são construídos a partir de discursos anteriores. Desse modo, o binômio ler/escrever representaria a gênese de toda construção textual.

Na citação, ou em qualquer outra prática intertextual, a repetição seria paradoxalmente irrepetível, na medida em que uma diferença sempre se instaura quando um fragmento textual adentra outro contexto. A repetição com diferença é o que leva a uma nova percepção desse texto por parte do leitor contemporâneo. Ao efetuar sua leitura, este se defronta com elementos que não haviam sido percebidos, explicitados ou sequer existiam no contexto original de criação. Nesse sentido, há apenas uma manipulação e montagem da linguagem em favor do que está sendo construído no presente da escrita.

Compagnon (1996) afirma que, para formar um tecido textual, o leitor precisa demarcar o território a ser explorado. Para isso, haveria dois procedimentos anteriores à citação, simultâneos ao ato de leitura: a acomodação e a solicitação 
(COMPAGNON, 1996). A primeira é a leitura da observação e da contemplação, em que o leitor se vê diante do texto e explora aquilo que lhe é agradável, mas apenas com os olhos. Já a segunda é a leitura do namoro, do toque, na qual haverá o contato físico - algo erótico - entre quem lê e o papel onde o texto se encontra.

Esses dois processos de citação, ainda no ato de leitura, transportam-se para Pride and Prejudice and Zombies através da primeira fase do processo de construção do texto, em que a leitura possibilitou demarcar o território a ser explorado. Quando o escritor norte-americano leu Orgulho e Preconceito, o que fazia na verdade era a leitura da acomodação. Como leitor, Grahame-Smith buscou no texto aquilo que lhe agradava e que lhe serviria, apenas através do olhar. Já na leitura da solicitação, Grahame-Smith, dedilhando o texto de Austen com extensões digitais de sua mão - a ponteira do mouse -, deixou-se guiar pela excitação, recortando, copiando e colando trechos para o corpo de sua própria obra.

Compagnon apresenta o grifo como outra alternativa para a citação. Grifar é contornar, sublinhar aquilo que é mais importante, citá-lo em outro contexto; é um modelo de recorte. Para Compagnon (1996), o grifo é uma prova de que a citação ocorre no próprio ato de leitura, sendo sua manifestação visual. O efeito do grifo no texto eleva a importância de determinadas partes em detrimentos de outras.

Enquanto lia Orgulho e Preconceito e o demarcava com "grifos em vermelho" (KELLOGG, 2009), Grahame-Smith já buscava apenas aquilo que lhe serviria. Os grifos coloridos em Orgulho e Preconceito foram o primeiro sinal de que outro texto surgiria. O grifo vaticinava a construção da obra-zumbi.

Nesse sentido, Grahame-Smith, usando de sua liberdade poética, acomoda-se perante o texto austeniano e solicita somente aquilo que lhe interessa em Austen. Por outro lado, o conjunto textual formado por Orgulho e Preconceito não contém certos elementos necessários a Pride and Prejudice and Zombies, os quais foram enxertados pelo escritor norte-americano. A esse respeito, no primeiro parágrafo do romance, o narrador dá uma prévia ao leitor do que este encontrará ao longo da leitura.

It is a truth universally acknowledged that a zombie in possession of brains must be in want of more brains. Never was this truth more plain than during the recent attacks 
at Netherfield Park, in which a household of eighteen was slaughtered and consumed by a horde of the living dead" (AUSTEN; GRAHAME-SMITH, 2009, p.7, grifo nosso). ${ }^{6}$

No texto de Austen, o trecho análogo seria este:

It is a truth universally acknowledged, that a single man in possession of a good fortune, must be in want of a wife.

However little known the feelings or views of such man may be on his first entering a neighbourhood, this truth is so well fixed in the mind of the surrounding families, that he is considered the rightful property of some one or other of their daughters (AUSTEN, 2008, p.5, grifo nosso).?

Nessas passagens, nota-se que single man foi substituído por zombie, good fortune por brain, e wife pelo plural brains. Grahame-Smith realiza um desvio mínimo na linguagem ao retirar os substantivos e adjetivos para inserir os zumbis, o cérebro e os cérebros, no que altera o foco do texto-fonte, que se concentrava no plano do matrimônio: o casamento como forma de sobrevivência para a mulher e de liberdade para o homem.

Os zumbis, então, subvertem a noção de casamento presente no romance de Austen. A busca pelo matrimônio ainda vai existir no texto, porém, para Grahame-Smith, o foco não recai sobre ele. Ao desviar o foco do casamento, o escritor norte-americano enfatiza que houve um desvio de significação em relação ao texto-base.

No segundo parágrafo de Austen, o narrador afirma

6 Traduçãonossa:Éuma verdade universalmente reconhecida que um zumbi em posse de um cérebro deve estar em busca de mais cérebros. Nunca isso foi tão evidente quanto nos recentes ataques em Netherfield Park, quando um grupo de dezoito empregados domésticos foram abatidos e consumidos por uma horda de mortos vivos.

7 É uma verdade u n iversalmente reconhecida que um homem solteiro, possuidor de uma grande fortuna, deve estar busca de uma esposa. que essa verdade está tão enraizada nas famílias que toda a vizinhança sabe que o jovem que chega já é de posse de alguma família, exceto ele mesmo. Grahame-Smith juntou os dois parágrafos da autora e uma nova verdade surge entre eles. A morte dos dezoito empregados remete a um novo cenário que surge dentro da narrativa, quando, ao invés de buscar pelo sustento em um casamento, deve-se lutar pela sobrevivência.

Esses parágrafos introdutórios do romance são seguidos da descrição da primeira cena em que o casal Bennet discute sobre a necessidade de visitar o vizinho Charles Bingley. Em Pride and Prejudice and Zombies, o Sr. Bennet está na sala de sua casa limpando seu mosquete, enquanto sua esposa está ao seu lado lhe dizendo o porquê de ter de visitar o novo vizinho. Grahame-Smith descreve o Sr. Bennet como um homem "tão peculiar de perspicácia, humor sarcástico, reserva 
e autodisciplina que a convivência de 23 anos havia sido insuficiente para que a esposa lhe entendesse o temperamento" (AUSTEN; GRAHAME-SMITH, 2010, p.8). Por sua vez, sua esposa foi descrita apenas como uma mulher de pouca inteligência, pouca instrução e que perdia tempo com tradições que pareciam supérfluas aos demais.

Quando o narrador de Pride and Prejudice and Zombies afirma que a Sra. Bennet era uma mulher apegada a velhos costumes e que estes no contexto do novo romance não teriam validade, ou tanta importância, há, no plano do enunciado, uma referência metatextual à quebra de tradições, sejam literárias ou sociais. Nesse processo, o autor se desfaz, de forma sutil, do que seria a essência do texto austeniano, em um processo de ablação, como define Compagnon (1996). Trata-se de uma espécie de mutilação ou desenraizamento de uma estrutura, ou partes dela, em benefício de formar outro corpo.

Outro exemplo desse processo pode ser visto no romance quando Charlotte Lucas é contaminada pelos zumbis durante uma visita aos Bennet. Como consequência desse evento, os Collins são retirados da narrativa: Charlotte morre contaminada pela estranha praga, enquanto seu marido, o Sr. Collins, se suicida. Com a morte dos Collins, o autor buscou outras formas de preencher o espaço deixado por estes personagens, aumentando a participação dos outros habitantes do condado de Hertfordshire no enredo.

Além da ablação, pode-se pensar em outras formas de composição textual análogas ao sistema da citação e relacionadas ao campo semântico do corte e da fenda, embora não exploradas por Compagnon. Tais procedimentos, comuns no campo da medicina cirúrgica, são a incisão e a excisão. Esta refere-se à extração de órgãos ou pequenas partes do corpo; à saída daquilo que não pertence ao corpo, ou que não se adapta a ele, por estar em um lugar que não lhe corresponde. Já aquela é a simples abertura do corpo para extração de algo. A incisão abre pequenos espaços no corpo, enquanto a excisão retira e deixa o espaço livre para receber outros elementos. As práticas de incisão e excisão em Orgulho e Preconceito retiram aquilo que a priori não cabe dentro do que o texto agora precisa passar a seu leitor, em tempos de literatura de massa e mashups literários.

Tais procedimentos ocorrem quando se retira uma parte do texto para dar lugar aos zumbis, quando se abrem pequenos 
8 Tradução nossa: No curso de uma pequena, mas perigosa caminhada de Longbourn vivia uma família da qual os Bennet eram particularmente muito íntimos. Sir William Lucas havia sido um fabricante de vestimentas para sepultamentos de tão fina beleza que o rei resolveu nomeá-lo cavaleiro. Ele havia feito uma considerável fortuna, até que a estranha praga tornou seus serviços desnecessários. Poucos pensavam que valiam a pena os custos de vestir seus mortos elegantemente, quando eles logo iriam sujar-se ao rastejar para fora de seus túmulos. Ele havia se mudado com a família para uma casa a cerca de uma milha de Meryton.

9 No curso de uma pequena caminhada de Longbourn vivia uma família da qual os Bennets eram particularmente muito intimos. Sir William Lucas, a princípio, foi um comerciante em Meryton, onde havia feito uma considerável fortuna e havia sido condecorado como cavalheiro por um decreto do rei, durante em seu mandato. A distinção tenha talvez sido sentida fortemente. Isso deu a ele desgosto para com seus negócios e com sua residência em uma pequena cidade mercantil; e saindo de ambas, ele se mudou com sua família para uma casa cerca de uma milha de Meryton, denominada a partir daquele momento de Lucas Lodge, onde ele poderia se deleitar com prazer por sua importância, e sem o impedimento de seus negócios, se ocuparia em ser cortês com todos. Pois, embora tenha-se elevado de posicão social não se tornara arrogante pelo contrário, ele era só atencão para com todos. Inofensivo, amigável e obsequioso por natureza, sua apresentação em St. James o tornara um artesão (AUSTEN, 2008, p.21 - edição bilíngue). trechos num parágrafo para a inserção de uma palavra, ou quando se expande uma cena para observar as reações das personagens na invasão dos zumbis.

$$
\text { À guisa de exemplo, no capítulo } 5 \text { de Pride and Prejudice }
$$

and Zombies, lê-se a seguinte passagem:

Within a short though perilous walk of Longbourn lived a family with whom the Bennets were particularly intimate. Sir William Lucas had been formerly a maker of fine burial gowns of such stately beauty that the King had seen fit to knight him. He had made tolerable fortune, until the strange plague had rendered his services unnecessary. Few thought it worth the expense to dress the dead in finery when they would only soil it upon crawling out of their graves. He had removed with his family to a house about a mile from Meryton (AUSTEN; GRAHAME-SMITH, 2009, p.17, grifo nosso). ${ }^{8}$

Este mesmo início de capítulo em Orgulho e Preconceito lê-se da seguinte forma:

Within a short walk of Longbourn lived a family with whom the Bennets were particularly intimate. Sir William Lucas had been formerly in trade in Meryton, where he had made a tolerable fortune, and risen to the honour of knighthood by an address to the king during his mayoralty. The distinction had perhaps been felt too strongly. It had given him a disgust to his business, and to his residence in a small market town; and, in quitting them both, he had removed with his family to a house about a mile from Meryton, denominated from that period Lucas Lodge, where he could think with pleasure of his own importance, and, unshackled by business, occupy himself solely in being civil to all the world. For, though elated by his rank, it did not render him supercilious; on the contrary, he was all attention to everybody. By nature inoffensive, friendly, and obliging, his presentation at St. James's had made him courteous (AUSTEN, 2008, p.21, grifo nosso). ${ }^{9}$

Em ambas as passagens, os narradores iniciam a apresentação dos Lucas, vizinhos dos Bennet. Note-se, porém que, em Austen, a distância entre a residência dos Bennet e a dos Lucas era curta (e, portanto, calma, sem oportunidade para grandes contratempos). Já no texto hibridizado com o discurso de Grahame-Smith, abre-se, por meio de uma incisão, a "curta caminhada" e enxertam-se zumbis, tornando a jornada perigosa. 
Além disso, o parágrafo tem sua parte final retirada em Pride and Prejudice and Zombies. Isso não compromete o entendimento acerca do que está sendo tratado neste trecho; aliás, acentua o que está sendo exposto, por meio de excisão que deixa à mostra a imagem acrescida em Pride and Prejudice and Zombies: os impactos da invasão zumbi sobre o negócio de Sir William Lucas.

A fim de aprofundar as discussões realizadas, na próxima seção, apresentamos a hibridização como procedimento textual na construção de Pride and Prejudice and Zombies. A partir desse fenômeno, pontuamos teorias que elucidam a abertura do texto para novas significações, a fim de indagar os efeitos desse processo na tessitura da obra-zumbi.

\section{A hibridização como procedimento zumbificador do romance}

Além dos procedimentos retirados das teorias de Compagnon, analisados na seção anterior, Grahame-Smith também submeteu Orgulho e Preconceito ao processo de transculturação - termo cunhado na antropologia para contestar o termo "aculturação", sendo posteriormente trazido para os estudos literários por Angel Rama (2001).

O conceito de transculturação enfoca ainda "um processo a partir do qual decorre uma nova realidade, transformada e complexa, uma realidade que não é um aglomerado mecânico de traços, nem mesmo um mosaico, mas um novo fenômeno, original e independente" (HARNNEZ, 1997, p.27). Assim, podemos tomá-lo emprestado para explicar como se deu o processo de adaptação de Orgulho e Preconceito para o texto zumbificado, em que a interação entre os dois autores resultou na perda de certos elementos por parte de Austen para inserção de outros por parte de Grahame-Smith.

Rama (2001) divide o processo de transculturação na literatura em três níveis: a) nível linguístico; b) nível da enunciação, na composição literária; c) nível dos significados. Os dois primeiros níveis podem ser observados no processo de feitura do texto de Pride and Prejudice and Zombies, na imbricação das vozes de Austen e Grahame-Smith, em suas distintas estratégias narrativas e usos linguísticos separados por dois séculos. Entretanto, é importante notar nesta análise que o 
${ }^{10}$ Nesta pesquisa consultamos diferentes fontes que empregam, ora com distintas ora com equivalentes nuances semânticas, os termos "hibridismo", "hibridação", "hibridez" e "hibridização" para designar a mistura de diferentes elementos. Para fins de padronização, privilegiamos neste texto o uso do termo "hibridização" proposto por Bakhtin em Questões de literatura e estética: a teoria do romance (2014). terceiro nível da transculturação não se consolida totalmente em Pride and Prejudice and Zombies, na medida em que a entrada dos zumbis, embora altere significativamente o texto, não altera alguns dos valores subjacentes ao romance de Austen, como, por exemplo, a temática do casamento e o conflito entre a burguesia rural e a aristocracia inglesa. Isso só seria possível se Pride and Prejudice and Zombies não tivesse a massa textual de Austen. A confluência total dos três níveis só aconteceria se Grahame-Smith tivesse se apropriado e transplantado o texto austeniano totalmente para o século XXI.

Desde o título "Pride and Prejudice and Zombies", que é em si mesmo já um mashup, tem-se um fenômeno de transculturação recorrente na cultura contemporânea, principalmente na criação literária: a hibridização ${ }^{10}$. Esse fenômeno se relaciona ao caráter da dupla consciência da linguagem, que se reconhece fragmentária e incompleta, com constante movimento e diálogo entre suas partes. A hibridização se constitui por ser uma característica essencial na construção da linguagem, pois é por meio dela que o entrelaçamento entre diferentes formas linguísticas é possível, fomentando, na visão bakhtiniana, sua própria evolução. Bakhtin emprega o termo "hibridização" para designar uma

mistura de duas ou mais diferentes linguagens sociais no interior de um único enunciado, [...] o reencontro na arena deste enunciado de duas consciências linguísticas, separadas por uma época, por uma diferença social (ou por ambas) das línguas (BAKHTIN, 2014, p.156).

Ainda para Bakhtin (2014), a hibridização pode ocorrer de duas formas: intencional ou involuntária. Esta acontece naturalmente quando situamos em um mesmo contexto diferentes elementos, cuja mistura se torna inevitável, como ocorreu no processo de colonização imposto aos países africanos. Já a hibridização intencional é criada propositalmente através de procedimentos estético-literários com fins de expressão e representação. Um dos papéis fundamentais do uso da hibridização na linguagem literária é garantir à estética romanesca sua mutabilidade.

O conceito de hibridização proposto por Bakhtin tornase, então, procedimento estético básico na composição de Pride and Prejudice and Zombies: há claramente duas vozes que 
11 Tradução nossa: “O que você quer dizer? E virando-se ele olhou por um momento para Elizabeth, até captar seu olhar; ele desviou o olhar e disse friamente, "ela é tolerável, mas não bonita o suficiente para me tentar; eu não estou com humor para dar atenção a moças que tenham sido desprezadas por outros homens".

Assim que o Sr. Darcy se afastou, Elizabeth sentiu o sangue gelar. Nunca tinha sido tão insultada em toda a sua vida. O código de guerreiros exigia que ela vingasse sua honra. Elizabeth abaixou até seu tornozelo, com muito cuidado para não chamar atenção. Lá, sua mão encontrou a adaga oculta sob seu vestido. Ela pretendia seguir o orgulhoso Sr. Darcy até o lado de fora e abrir a garganta dele". emergem do texto, fazendo conviver na mesma arena simbólica duas culturas e contextos diferentes, os quais, assim como os zumbis, lutam cada um pelo seu espaço, desconstruindo-se, reconstruindo-se e dando origem a um novo discurso.

Para tanto, ressignificam-se a tradição e a contemporaneidade literária, em uma poética do desmonte e do remonte, em que, em paralelo à alteração formal do romance, há uma ressignificação do que permanece inalterado no texto (pelo menos na tessitura dos significantes). No caso de Orgulho e Preconceito, o que permanece na quase totalidade de suas releituras (e também em Pride and Prejudice and Zombies) são dois dos principais motivos desse romance, ainda que ressignificados pelas alterações no seu entorno textual.

O primeiro motivo preservado na releitura é a ideia de manual de casamento para as moças do século XIX, em que há uma busca pelo homem perfeito, bonito e rico, representado pelo Sr. Darcy em Orgulho e Preconceito. Tal imagem, cara aos romances do período regencial inglês, exige das personagens femininas de Austen uma série de comportamentos regidos por códigos oitocentistas. Em Pride and Prejudice and Zombies, o matrimônio permanece como fim para o qual caminham as personagens, mas tal destino ganha novos matizes interpretativos na medida em que ao manual de casamento a que se presta o texto original soma-se outro manual: o código de honra Shaolin que devem seguir as lutadoras da família Bennet:
"Which do you mean?" and turning round he looked for a moment at Elizabeth, till catching her eye, he withdrew his own and coldly said, "She is tolerable, but not handsome enough to tempt me; I am in no humour at present to give consequence to young ladies who are slighted by other men."
As Mr. Darcy walked off, Elizabeth felt her blood turn cold. She had never in her life been so insulted. The warrior code demanded she avenge her honour. Elizabeth reached down to her ankle, taking care not to draw attention. There, her hand met the dagger concealed beneath her dress. She meant to follow this proud Mr. Darcy outside and open his throat (AUSTEN; GRAHAME-SMITH, 2009, pp.13-14, grifo nosso). ${ }^{11}$

Se a cena acima claramente retoma o baile em que, em Orgulho e Preconceito, Darcy pela primeira vez despreza abertamente Elizabeth, a reação da protagonista aqui é 
12 Tradução nossa: "A Inglaterra permaneceu sob a sombra de Satã. Os mortos continuaram a cavar seu caminho entre suas criptas e caixões, banqueteando-se com cérebros britânicos. Vitórias e r a m celebradas e derrotadas lamentadas. E as irmãs Bennet - servas de Sua Majestade, protetoras de Hertfordshire, mantenedoras dos segredos de Shaolin e noivas da morte eram agora, três delas, esposas, suas espadas aquietadas pela única força mais poderosa que qualquer guerreiro". outra: o código da corte e do flerte oitocentista, em que uma moça deveria saber lidar com o desprezo de um parceiro em potencial (não cabendo a ela a decisão final de quais relações amorosas se estabeleceriam ou não), ganha novos sentidos diante do código de honra Shaolin, que leva a moça a sacar a adaga para cortar a garganta do homem que a desrespeitara, no lugar de apenas abrir seu leque ruborizada.

O segundo motivo estruturante de Orgulho e Preconceito que se mantém na releitura de Pride and Prejudice and Zombies, mas com ressignificações propiciadas pela adição dos zumbis, é o casamento entre amantes de classes sociais distintas, que vivem em conflitos ao longo da narrativa, mas, no final, fazem as pazes, casam e são "felizes para sempre".

England remained in the shadow of Satan. The dead continued to claw their way through crypt and coffin alike, feasting on British brains. Victories were celebrated, defeats lamented. And the sisters Bennet - servants of His Majesty, protectors of Hertfordshire, beholders of the secrets of Shaolin, and brides of death - were now, three of them, brides of man, their swords quieted by that only force more powerful than any warrior (AUSTEN; GRAHAME-SMITH, 2009, p.317). ${ }^{12}$

Se a felicidade conjugal após os desencontros ao longo da narrativa permanece na releitura, esta é pontuada por outros elementos que introduzem diferenças semânticas ao que há de "mesmo" entre os textos. Em Pride and Prejudice and Zombies, a luta que o fim da narrativa encerra não é só a da batalha por um marido, senão também a que se trava contra os zumbis. Esta, porém, continua em Hertfordshire, haja vista que a praga não fora erradicada. Saem de combate apenas as irmãs Bennet casadas, sob o argumento de que o amor é uma força maior do que seu espírito guerreiro, o que, em certa medida, reproduz na leitura do século XXI estereótipos femininos do século XIX.

Tal dialética entre permanência e mudança se dá na manipulação das camadas de expressão e de conteúdo do romance, eternizando o próprio processo de evolução morfossintática e semântica da linguagem e, portanto, da literatura. Nesse sentido, a roda temporal da criação textual gravita em volta da noção de apropriação como forma de escrita que invoca outros estilos, aqui no sentido de tomar emprestado, como a paródia. 
Para Affonso Romano de Sant'Anna (1985), o autor de uma apropriação não escreve; ele transcreve. A transcrição total do texto seria o plágio, enquanto uma transcrição parcial seria uma paráfrase. Assim, a apropriação contestaria a noção de propriedade, pois seu intuito é o de dessacralizar, tirar a aura do sagrado: "o que caracterizaria a noção de apropriação é a dessacralização, o desrespeito à obra do outro" (SANT'ANNA, 1985, p.46).

O processo de apropriação pode ocorrer em primeiro e segundo graus. Neste, retoma-se o conteúdo do texto original para contar uma nova história (SANT'ANNA, 1985): seu enredo é transplantado para outros canais ou contextos, como ocorre com adaptações fílmicas mais contemporâneas. Esse tipo de apropriação é explicitamente definido em legendas como "baseado no romance de", ou "uma adaptação moderna do romance de", ou "adaptação livre de", que remetem ao uso indireto do texto matriz. Tais legendas marcam a adaptação como um objeto derivado de outro: uma literatura de segunda mão.

Já na apropriação de primeiro grau, o próprio objeto imitado entraria em cena (SANT'ANNA, 1985), como no caso de Pride and Prejudice and Zombies, em que não apenas o enredo, mas a massa textual de Austen se encontra presente. O nome da autora Jane Austen na capa do romance, acompanhado do título da obra que é, em parte, Pride and Prejudice [and Zombies], já demonstra que houve apropriação de primeiro grau.

Esse processo de apropriação ainda pode ser observado em dois níveis discursivos: na fala do narrador e na dos personagens. O primeiro diz respeito ao que ocorre no interior do romance quando, através da voz do narrador, emerge um enunciado híbrido que congrega as vozes de Austen e Grahame-Smith, conforme se pode notar nos excertos anteriormente transcritos neste artigo.

O segundo nível da apropriação se observa no discurso híbrido que emerge quando na adaptação se inserem novos elementos no discurso dos personagens que já existiam no texto de Austen. Por exemplo, observa-se tal procedimento no capítulo 36 de Pride and Prejudice and Zombies, no qual Elizabeth Bennet, que, no capítulo anterior, havia recebido a carta do Sr. Darcy com as explicações sobre o comportamento deste diante de Bingley, Jane e Wickham, começa a refletir com 
${ }^{13}$ Tradução nossa: "Quãodesprezivelmente tenho eu agido", ela exclamou; "eu que sempre tive orgulho de mim mesma pelo meu discernimento! Eu, que tenho me valorizado pelo controle da minha mente e corpo! que tenho frequentemente $\mathrm{d}$ e s d e $\mathrm{nh}$ a d o d a generosidade da minha irmã, e gratificado minha vaidade com uma suspeita inútil! Que humilhante é esta descoberta! Oh! Se meu mestre estivesse aqui para sangrar minhas costas com bambu molhado.

14 "Quão desprezivelmente eu agi", ela exclamou; "eu me orgulhava de meu discernimento! Eu, que dava valor a mim mesma pelas minhas habilidades! Que frequentemente desdenhava o generoso candor de minha irmã e satisfazia minha vaidade com a inútil $e$ culpada desconfiança! Quão humilhante é esta descoberta! Ainda que humilhação! Estivera eu apaixonada e não poderia ter sido mais ruinosamente cega! Mas a vaidade, e não o amor, tem sido minha fantasia. Agradada com a preferência de um e ofendida pela negligência de outro, bem no começo de nosso relacionamento. Cortejei a prepotência e a ignorância, e joguei a razão para longe, no que se referia a ambos. Até agora, eu não conhecia a mim mesma" (AUSTEN, 2008, p.220, edição bilíngue). maior atenção sobre o conteúdo da carta. A protagonista emite o segundo discurso sobre si mesma:
"How despicably I have acted!", She cried; "I, who have prided myself on my discernment! I, who have valued myself on my mastery of mind and body! Who have often disdained the generosity of my sister, and gratified my vanity in useless mistrust! How humiliating is this discovery! Oh! Were my master here to bloody back with wet bamboo" (AUSTEN; GRAHAME-SMITH, 2009, p.165, grifo nosso).$^{13}$

No nível da enunciação, Grahame-Smith faz uma excisão no trecho homólogo do romance de Austen suprimindo a metade final do parágrafo. $\mathrm{O}$ autor substituiu ainda "as habilidades" por "controle de mente e do corpo"; o adjetivo "generoso" pelo substantivo "generosidade"; e acrescentou um novo desfecho para a fala da protagonista. O mesmo parágrafo em Austen aparecia da seguinte forma:
"How despicably I have acted!" she cried; "I, who have prided myself on my discernment! I, who have valued myself on my abilities! who have often disdained the generous candour of my sister, and gratified my vanity in useless or blameable mistrust! How humiliating is this discovery! Yet how just a humiliation! Had I been in love, I could not have been more wretchedly blind! But vanity, not love, has been my folly. Pleased with the preference of one, and offended by the neglect of the other, on the very beginning or our acquaintance, I have courted prepossession and ignorance, and driven reason away, where either were concerned. Till this moment I never knew myself" (AUSTEN, 2008, p.220, grifo nosso). ${ }^{14}$

Uma outra dimensão da apropriação no discurso dos personagens se dá na "fala" dos zumbis, uma linguagem onomatopaica que aparece apenas quando o narrador fala em discurso indireto por eles. Em todas as cenas dos ataques dos zumbis, não há qualquer rosnado ou gemido emitido diretamente pelas criaturas, o que sugere um duplo jogo na palavra "não mencionável", usada no romance para se referir aos mortos vivos: os personagens pouco mencionam a palavra "zumbi", em um claro tabu onomástico, mas os não mencionáveis também nada mencionam, pois, em geral, não emitem som algum. "Não mencionável" tornase, então, sinônimo de "não mencionante". Seres que não devem ser mencionados, ou lembrados, mas também não 
15 "Devemos nos encontrar muitas vezes, espero, em Hertfordshire".

“Não devo deixar Kent por algum tempo. Prometa-me, portanto ir até Hunsford".

Elizabeth não poderia recusar, embora ela previsse pouco prazer na visita.

"Meu pai e Maria irão me ver em março", acrescentou Charlotte, "e espero quer você consinta em fazer parte do grupo. De fato, Eliza, você será toa bem-vinda quanto qualquer um deles".

Ocasamento aconteceu; [...] a noiva e o noivo partiram para Kent na porta da igreja e todos tinham tanto a dizer ou a ouvir sobe o assunto quanto o habitual (AUSTEN, 2010, p.158 edição bilíngue). podem "mencionar", ou emitir discurso algum, os zumbis são criaturas abjetas, que vivem à margem da sociedade oitocentista, em florestas e alamedas, sendo seus discursos mesmo em linguagem onomatopaica - invalidados, pois são apenas repassados por meio da voz do narrador.

Em Pride and Prejudice and Zombies, Charlotte Lucas é o único personagem a passar pelo processo de zumbificação diante dos olhos do leitor, e se torna, por conseguinte, o único zumbi a ter sua fala registrada em discurso direto. Após ser mordida, Charlotte torna-se gradativamente uma morta-viva e inicia seu processo de transformação começando a apresentar traços de deterioração da fala, engolindo frases ou mudando as letras das palavras. Vê-se aí claramente sua enunciação zumbi, mas não apenas por meio de uma menção a essa apropriação linguística em discurso indireto, como acontece nos outros casos.

No capítulo 28 de Orgulho e Preconceito, acontece o casamento entre Charlotte Lucas e o Sr. Collins. Em um dos parágrafos, observa-se uma conversa entre ela e Elizabeth, seguida da descrição do casamento.

"We shall often meet, I hope, in Hertfordshire."

"I am not likely to leave Kent for some time. Promise me, therefore, to come to Hunsford."

Elizabeth could not refuse, though she foresaw little pleasure in the visit.

"My father and Maria are coming to me in March," added Charlotte, "and I hope you will consent to be of the party. Indeed, Eliza, you will be as welcome as either of them."

The wedding took place; [...] the bride and bridegroom set off for Kent from the church door, and everybody had as much to say, or to hear, on the subject as usual" (AUSTEN, 2008, p.158). ${ }^{15}$

Em Pride and Prejudice and Zombies, observa-se a seguinte descrição do mesmo evento:

"We shall often meet, I hope, in Hertfordshire."

"I am not likely to leave Kent for some time. Promise me, therefore, to come to Hunsford." Elizabeth could not refuse, though she foresaw little pleasure in the visit. Charlotte was already showing the earliest signs of transformation, though she took great care to hide them from all but the 
16 Tradução nossa:

"Espero que nos encontremos com f re quência e m Hertfordshire".

"Provavelmente, não poderei por algum tempo deixar Kent. Por esse motivo, prometa-me, que virá a Hunsford". Elizabeth não pôde recusar, embora previsse que não teria prazer algum na visita. Charlotte já estava evidenciando os primeiros sinais da transformação, embora tivesse muito cuidado em escondê-lo de todos, exceto olhos treinados. Sua pele começara a empalidecer e sua fala parecia custosa.

"Meu pai e Maria virão me ver em março", acrescentou Charlotte, "e eu espero que você concorde em fazer parte do grupo. De fato, Eliza, você será tão bem-vinda quanto qualquer um deles".

O casamento aconteceu e ninguém além de Elizabeth parecia suspeitar da condição da noiva. $\mathrm{O}$ Sr. Collins parecia mais feliz do que nunca, apesar do fato de Charlotte ter de ser lembrada de usar o garfo várias vezes ao longo do jantar. A noiva e o noivo partiram para Kent da porta da igreja, e como de costume todo mundo tinha muito a dizer ou a ouvir.

17 Tradução nossa: "Wade Caferine muito respeitável... mulher sensata", grunhiu Charlotte, "e uma fi-zi-a muito atenta". trained eye. Her skin had taken on a slight pallor, and her speech seemed a trifle laboured.

"My father and Maria are coming to me in March," added Charlotte, "and I hope you will consent to be of the party. Indeed, Eliza, you will be as welcome as either of them."

The wedding took place, and no one other than Elizabeth seemed to suspect the bride's condition. Mr. Collins appeared happier than he ever had despite the fact that Charlotte had to be reminded to use her fork several times over the course of dinner. The bride and bridegroom set off for Kent from the church door, and everybody had as much to say, or to hear, on the subject as usual (AUSTEN; GRAHAME-SMITH, 2009, pp. 110-112, grifos nossos).$^{16}$

Em ambos os excertos, descreve-se o momento da união dos Collins (Charlotte e William). No início de ambos os trechos, Charlotte pede que Elizabeth vá visitá-la em Hunsford. A amiga reflete que não pode recusar o convite, mas terá pouco prazer na visita. Em Orgulho e Preconceito, presume-se que Elizabeth terá pouco prazer em visitar a amiga pelo fato de ter ela mesma recusado a proposta de casamento do Sr. Collins. Na obra-zumbi, o fato de Elizabeth não ter prazer com a visita estaria no fato de não querer presenciar o processo de zumbificação da amiga, o qual se observa na parte final do segundo parágrafo, destacado acima em negrito. Logo, Charlotte teria de ser morta, pois já apresentava os primeiros sinais de zumbificação através da palidez da pele e da dificuldade no ato de fala, ressaltada mais à frente no romance em discurso direto, por meio de palavras mal pronunciadas aqui destacadas em negrito: “Wade Caferine very respectable... sensible woman", groaned Charlotte, "and most attentive naybah $^{17 "}$ (AUSTEN; GRAHAME-SMITH, 2009, p.121).

Conforme analisado, para a construção dessa cena, um processo de mutilação e hibridização foi perpetrado em dois níveis sobre o texto: primeiro, houve a junção de parágrafos, colagem de enxertos, excisões e incisões no discurso do narrador, que passa a falar por Austen e Grahame-Smith; ademais, a neófita zumbi Charlotte reproduz em seu discurso um misto de dicções do século XIX e uma cacofonia de mortaviva da horda zumbi, tão cara ao século XXI.

Assim, todo o processo de zumbificação do romance Pride and Prejudice and Zombies, hibridizando os discursos de Austen e Grahame-Smith (a autora morta e o autor vivo - autoria morto- 
viva?) conflui para a personagem Charlotte Lucas, que devém zumbi diante de nossos olhos, tal qual se dá com o próprio romance. Trata-se, pois, de uma hibridação entre Charlotte Lucas e os zumbis, Jane Austen e Grahame-Smith, mortos e vivos; eis, afinal, o caráter ambivalente da obra-zumbi.

\section{Considerações finais}

A citação e a hibridização são necrofilias textuais, pois, ensejam um contato corpo a corpo, em que se manipulam as entranhas do texto. Como a força que pressiona o texto a se deslocar, o processo de absorção pelo corpo textual daquilo que não lhe pertence requer a presença de outros dois processos cirúrgicos: a extirpação e o enxerto (COMPAGNON, 1996). Tais procedimentos são necessários para a formação do novo texto, na medida em que deve haver uma expulsão ou deslocamento daquilo que é considerado dispensável para a formação da nova massa textual, em favor daquilo que está sendo formado.

Nesse diapasão, o presente artigo leu Pride and Prejudice and Zombies à luz dos procedimentos de intertextualidade e hibridização que permitem a construção de uma obra$z u m b i$ a partir de operações de corte, colagem e costura entre discursos do século XIX e do século XXI, de diferentes autores, continentes, tempos e, quiçá, gêneros. Identificaramse, nesta análise, procedimentos micro e macrotextuais que ressignificam a narrativa de Austen, à luz da invasão zumbi cara à cultura pop contemporânea, em um jogo dialético entre permanência e mudança, cânone e literatura de massa, tradição e comercialização.

Pride and Prejudice and Zombies revela-se, pois, como um romance cuja fala se dá a partir de um entre-lugar enunciativo. A presença dos zumbis no texto austeniano descentra toda a narrativa e, consequentemente, mantém o texto em constante deslocamento. A obra-zumbi não é, portanto, uma adaptação como qualquer outra, pois a presença de grande parte da massa textual de Orgulho e Preconceito modifica a noção de adaptação que se observa em grande parte dos modelos atuais. Nesse sentido, a obra aqui analisada reflete a própria condição do gênero romance, que, ainda em processo de inacabamento, se mostra capaz de se metamorfosear e abarcar outros gêneros, como na composição do mashup literário. 


\section{REFERÊNCIAS}

AUSTEN, J. Orgulho e Preconceito. Tradução de Marcella Furtado. São Paulo: Landmark, 2008. Título original: Pride and Prejudice. AUSTEN, J.; GRAHAME-SMITH, S. Pride and Prejudice and Zombies. Philadelphia: Quirk Books, 2009.

BAKHTIN, M. Questões de literatura e de estética: a teoria do romance. 7.ed. - São Paulo: HUCITEC, 2014.

BARTHES, R. O prazer do texto. São Paulo: Perspectiva, 1987.

COLLINS, C. Pride and Prejudice and Zombies' author talks about his literary monster mash-up. Entertaiment weekly, 21 de fev. 2009. Disponível em: <http://www.ew.com/ article/2009/02/21/monster-mash-up>. Acesso em: 06 jun 2015. COMPAGNON, A. O trabalho da citação. Tradução de Cleonice P. B. Mourão. Belo Horizonte: Editora UFMG, 1996.

GOMES, A. S. Zumbis e vampiros e... Jane Austen: a emergência do mashup literário. Disponível em: <https://sobreomedo.files. wordpress.com/2012/04/Andersonsoaresgo

mes.pdf>. Acesso em: 24 jul 2013.

GROSSMAN, L. Pride and Prejudice, now with Zombies. Time Magazine, 02 de abr. 2009. Disponível em: <http://content. time.com/time/arts/article/0,8599,1889075,00.

html>. Acesso em: 22 dez 2014.

HANNERZ, U. Fluxos, fronteiras, híbridos: palavras-chave da antropologia transnacional. Revista Mana. V. 3.7 - 39, 1997.

KELLOGG, C. Pride and Prejudice and Zombies by Seth Grahame-Smith. Los Angeles Times, 04 de abr. 2009. Disponível em: <http://www.latimes.com/entertainment/la-et-zombies42009apr04-story.html>. Acesso em: $22 \mathrm{dez} 2014$.

MURPHY, J. Remix Culture and the Literary Mashup. Alluvium, Birbeck, Universidade de Londres, v. 2, n. 2 n. pag, 25 de mar. de 2013. Disponível em: <http://dx.doi.org/10.7766/alluvium. v2.2.02>. Acesso em: 04 set de 2015.

QUIRK BOOKS. Pride and Prejudice and Zombies: Deluxe Heirloom Edition. Disponível em <http://www.quirkbooks. $\mathrm{com} /$ book/pride-and-prejudice-and-zombies-deluxeheirloom-edition>. Acesso em: 07 set 2014. 
RAMA, A. Los processos de transculturação na narrativa latino-americana. In: AGUIAR, Flávio; VASCONCELOS, Sandra Guardini T. (Orgs.). Ángel Rama. Literatura e cultura na América Latina. Trad. Rachel La Corte dos Santos e Elza Gasparotto. São Paulo: EdUSP: 2001. Título original: Los processos de transculturacion de la narrativa latino-americana. SANT'ANNA, A. R. Paródia, paráfrase e cia. São Paulo: Ática, 1985. SANTANA, M. F. Orgulho e Preconceito (e Zumbis): o Diálogo entre o cânone e a narrativa pós-moderna. Curitiba, 2012, $124 \mathrm{f}$. Dissertação (Mestrado em Teoria Literária) - Uniandrade, 2012. SCHUESSLER, J. I was a regency zombie. The New York Times, 21 de fev. 2009a. Disponível em: <http://www.nytimes.com /2009/02/22/weekinreview/22schuessler.html ?fta $=\mathrm{y}>$. Acesso em: $22 \mathrm{dez} 2014$.

. Undead-Austen Mash-Ups. The New York Times, 13 de dez. 2009b. Disponível em: <http://query.nytimes.com/gst/ fullpage.html?res=9E05E3DC1E39F93

0A25751C1A96F9C8B63>. Acesso em: 22 dez 2014.

TAKAHASHI, D. Pride and Prejudice and Zombies by Jane Austen, Seth Grahame-Smith, Tony Lee, and Cliff Richards. Pasadena, 17 de mai. 2011. Disponível em: <http://ladykazumi. blogspot.com.br/2011/05/pride-and-prejudice-and-zombiesby-jane.html>. Acesso em: 06 jun 2015.

WILLIAMS, R. O campo e a cidade: na história e na literatura. São Paulo: Companhia das Letras, 1989. 


\section{Abstract \\ Pride and Prejudice and Zombies: A Zombified (Textual) Body}

At the end of the first decade of the new millennium, the publishing market saw the rise of a new form of textual composition, the literary mashup, which is produced by means of reading and writing movements that empower Barthes' understanding of texts as "tissues of quotations"; to do so, a mashup is based on procedures of fragmentation of a classic work so as to insert elements of contemporary pop culture in it. Pride and Prejudice and Zombies, by Jane Austen and Seth Grahame-Smith, was the pioneer of this trend, thus paving the way for a new wave in the industry of best-sellers produced through the same procedures. This paper analyzes the novel Pride and Prejudice and Zombies in order to understand, in terms of immanence, the procedures through which Austen's nineteenth century writing and GrahameSmith's contemporary writing were mixed in the entrails of the novel, thus molding a hybrid work, which is a zombie as well, since it lies between the writing of a dead author and that of a living one. Thereby, by adopting the image of the zombie not only as plot element, but also as a process of writing and adaptation - through the zombification of the novel by Jane Austen -, we aim to analyze the entrails of Pride and Prejudice and Zombies, based on the concept of literary mashup, the genre that gave rise to the mixture of different texts within the work by means of hybridization procedures.

Keywords: literary mashup; zombie; hybridization procedures. 